\title{
CHANGING PATTERN OF CUTANEOUS ADVERSE DRUG REACTION
}

\author{
Sadhna Kaushik1, Neeraj Srivastava², Vinay Kumar ${ }^{3}$
}

1 Professor, Department of Pharmacology, MLB Medical College, Jhansi, Uttar Pradesh, India.

${ }^{2}$ Associate Professor, Department of Dermatology, MLB Medical College, Jhansi, Uttar Pradesh, India.

${ }_{3}^{3} P S-P v A, A M C$ (PvPI), Department of Pharmacology, MLB Medical College, Jhansi, Uttar Pradesh, India.

\section{ABSTRACT}

\section{BACKGROUND}

Adverse drug reactions (ADRs) are unwanted or unintended effects of drugs, which occur during proper use of a drug. The pattern of cutaneous adverse drug eruptions and the drugs responsible for them had shown more or less similar pattern in various studies.

The objective of our study was to ascertain the changing pattern of clinical spectrum of ACDRs, the causative drugs and to find current trend in a tertiary care centre.

\section{MATERIALS AND METHODS}

All patients who attended the dermatology OPD/IPD of the hospital from 28-02-2016 to 20-05-2017 were screened. Suspected cases of ADRs were independently assessed by dermatology consultant of the department and subsequently causality assessment was done by causality assessment committee using WHO-UMC causality assessment scale. Only those cases where the causality was certain, probable/ likely or possible were recorded.

\section{RESULTS}

In the present study, total number of subjects was 98. Most common culprit drugs were antibiotics (47), in which fluoroquinolones + nitroimidazole (30) were most common causative agent. Fixed Drug Eruption (FDE) was the most common cutaneous ADR reported in our study. It occurred in $46.94 \%$ of patients. Morbilliform drug rash was the second most common cutaneous adverse drug reaction in $28.57 \%$ of patients.

\section{CONCLUSION}

From current study, it is concluded that FDE is becoming most prevalent type of cutaneous ADR than Morbilliform drug rash. Commonest culprit drug now are fluoroquinolones + Nitroimidazole combination followed by NSAIDs and Cephalosporins. Cutaneous ADRs are now less reported with sulphonamide, which were the most common culprit drug reported in previous studies.

\section{KEY WORDS}

Cutaneous Adverse Drug Reaction, Fixed Drug Eruption, Fluoroquinolones.

HOW TO CITE THIS ARTICLE: Kaushik S, Srivastava N, Kumar V. Changing pattern of cutaneous adverse drug reaction. J. Evolution Med. Dent. Sci. 2018;7(23):2793-2796, DOI: 10.14260/jemds/2018/630

\section{BACKGROUND}

Occurrence of unwanted effects during drug intake is called Adverse Drug Reaction (ADR). Cutaneous Adverse Drug Reaction (cADR) constitute $2 \%$ to $3 \%$ of patients attending the Outpatient Department (OPD). Majority of cutaneous ADRs are mild and are self-resolving, sometimes severe reactions like Stevens-Johnson Syndrome (SJS) and Toxic epidermal necrolysis (TEN) can occur, which constitute from $2.6 \%$ to $7 \%$ of cutaneous adverse drug reactions.

The pattern of cutaneous adverse drug eruptions and the drugs responsible for them had shown more or less similar pattern in various previous studies. This study was undertaken to determine the frequency of different type of CADR, identifying culprit drug groups and to compare the results with previous such studies to determine the changing pattern of CADR

'Financial or Other Competing Interest': None.

Submission 24-04-2018, Peer Review 18-05-2018,

Acceptance 25-05-2018, Published 04-06-2018.

Corresponding Author:

Dr. Neeraj Srivastava

Department of Dermatology,

PR-10, MLB Medical College Campus,

Jhansi, Uttar Pradesh, India,

E-mail: dermaneeraj@gmail.com

DOI: $10.14260 /$ jemds $/ 2018 / 630$

\section{MATERIALS AND METHODS}

All patients attending the Dermatology OPD of MLB Medical College, Jhansi from 28-02-2016 to 20-05-2017 were noted for occurrence of any CADR. Those cases in which CADR was suspected by dermatology consultant were recorded after being labelled as certain, probable and possible by causality assessment committee using WHO-UMC causality assessment scale were enrolled.

A detailed history of the patient was noted on a proforma that included the details of culprit drug, i.e. its duration, dosage, indication for intake etc. and required all necessary investigations were performed. The patient was subsequently followed till recovery occurred. Exclusion criteria were those cases in which drugs were unknown and if patients were taking ayurvedic or homeopathic medications. According to the University of Virginia Health System Adverse Drug Reaction Reporting Program Criteria, the CADR were classified as mild, moderate and severe. The results were tabulated, and a detailed comparison was made with previous such type of studies on CADR to observe the changes occurring in these patterns.

\section{RESULTS}

A total of 98 cutaneous ADR was reported, in this 67 by males and 31 by females. Mean of the population was 34.55 and it varied from minimum of 9 to maximum of 72 years of age 
(Table 1). Majority of patients were 31 - 45 years of age group, which was followed by 16 - 30 years of age group.

Most common cause for drug intake was diarrhoea in 24 patients followed by fever and pain in 12 patients each (Table 2). Other common causes were adverse effect occurring due to intake of antifungal (6), ATT (8) and ART (4). In all these cases, male patients were more common than compared to female patients. In majority (50) of patients, cutaneous adverse drug reaction was reported within 1 day of drug intake (Table 3). This was followed by ADRs reported on 2nd day in 21 patients. In 6 patients, cutaneous ADRs was suspected to be occurring after intake of drug for 1 week or more with maximum duration being 42 days in patient with Dapsone syndrome.

Fixed drug eruption was the most common adverse drug reaction being reported of 46 patients (39 males and 7 females) (Table 4). Morbilliform rash was the $2^{\text {nd }}$ most common cutaneous ADRs occurring in 28 patients (16 males and 12 females), other common cutaneous ADRs were SJS (4), photosensitive drug rash (3) and erythroderma (2).

Most common culprit drugs were antibiotics (47), which were followed by NSAIDs (23). Other drug groups which were common included ATT (8), antifungal (6) and ART (4) (Table 5). In antibiotics fluoroquinolones + nitroimidazole (30) antibiotics were most common followed by Cephalosporin III gen (5) and Penicillin (5) antibiotics. In NSAIDs, most common were non-selective Cox-inhibitor (12) i.e. combination of Ibuprofen and paracetamol followed by preferential Cox-2 inhibitor (8). In Antifungals, Triazoles (4) were most common followed by Allylamine (2). In ART, Nonnucleoside reverse-transcriptase inhibitors (NNRTIs) (4) were most common. In ATT (8), isoniazid (5) (Acneiform eruption) was most common culprit drug followed by pyrazinamide (2).

\begin{tabular}{|c|c|c|}
\hline Group & Male (\%) & Female (\%) \\
\hline $0-15$ & $2(2.04)$ & $1(1.02)$ \\
\hline $16-30$ & $25(25.51)$ & $13(13.27)$ \\
\hline $31-45$ & $31(31.63)$ & $12(12.24)$ \\
\hline $46-60$ & $7(7.14)$ & $2(2.04)$ \\
\hline$>60$ & $2(2.04)$ & $3(3.06)$ \\
\hline Total & $67(68.37)$ & $31(31.63)$ \\
\hline \multicolumn{3}{|c|}{ Table 1. Demographic Profile of CADR } \\
\hline
\end{tabular}

\begin{tabular}{|c|c|c|c|c|}
\hline \multirow{2}{*}{\multicolumn{2}{|c|}{ Indications }} & \multicolumn{2}{|c|}{ Sex } & \multirow{3}{*}{$\begin{array}{c}\text { Total } \\
24 \\
\end{array}$} \\
\hline & & \multirow{2}{*}{$\begin{array}{c}\mathbf{M} \\
18 \\
\end{array}$} & \multirow{2}{*}{$\begin{array}{l}\mathbf{F} \\
6 \\
\end{array}$} & \\
\hline 1. & Diarrhoea & & & \\
\hline 2. & Fever & 7 & 5 & 12 \\
\hline 3. & Pain & 7 & 5 & 12 \\
\hline 4. & ATT & 4 & 4 & 8 \\
\hline 5. & Fungal & 5 & 1 & 6 \\
\hline 6. & HIV & 2 & 2 & 4 \\
\hline 7. & Others & 24 & 8 & 32 \\
\hline \multicolumn{2}{|c|}{ Total } & 67 & 31 & 98 \\
\hline \multicolumn{5}{|c|}{ Table 2. Indications for Drug Intake } \\
\hline
\end{tabular}

\begin{tabular}{|c|c|c|c|c|c|c|c|}
\hline \multirow{2}{*}{$\begin{array}{c}\text { Period of } \\
\text { Manifestation }\end{array}$} & \multicolumn{6}{|c|}{ Adverse Reaction } & \multirow[b]{2}{*}{ Total } \\
\hline & $\begin{array}{c}\text { Morbilliform } \\
\text { Rash }\end{array}$ & FDE & SJS & Photosensitive Rash & Exfoliative Dermatitis & Others & \\
\hline 1. & 18 & 40 & 0 & 2 & 0 & 7 & 67 \\
\hline 2. & 4 & 4 & 0 & 1 & 0 & 0 & 9 \\
\hline 3. & 4 & 0 & 0 & 0 & 0 & 1 & 5 \\
\hline 4. & 2 & 1 & 0 & 0 & 0 & 0 & 3 \\
\hline 5. & 0 & 1 & 0 & 0 & 0 & 0 & 1 \\
\hline 6. & 0 & 0 & 2 & 0 & 0 & 1 & 3 \\
\hline 9. & 0 & 0 & 1 & 0 & 0 & 1 & 2 \\
\hline 10. & 0 & 0 & 0 & 0 & 0 & 1 & 1 \\
\hline 12. & 0 & 0 & 0 & 0 & 1 & 1 & 2 \\
\hline 15. & 0 & 0 & 1 & 0 & 0 & 0 & 1 \\
\hline$>30$ & 0 & 0 & 0 & 0 & 1 & 3 & 4 \\
\hline Total & 28 & 46 & 4 & 3 & 2 & 15 & 98 \\
\hline
\end{tabular}

Table 3. Time Period of Manifestation of CADR

\begin{tabular}{|c|c|c|c|c|}
\hline \multicolumn{2}{|c|}{ ADR } & \multicolumn{2}{|c|}{ Sex } & \multirow{2}{*}{ Total } \\
\cline { 3 - 4 } & & M & F & 28 \\
\hline 1. & Morbilliform rash & 16 & 7 & 46 \\
\hline 2. & FDE & 39 & 3 & 4 \\
\hline 3. & SJS & 0 & 3 & 3 \\
\hline 4. & Photosensitive rash & 1 & 1 & 2 \\
\hline 5. & Exfoliative dermatitis & 10 & 5 & 15 \\
\hline 6. & Others & $\mathbf{6 7}$ & $\mathbf{3 1}$ \\
\hline \multicolumn{2}{|c|}{ Table 4. Sex Distribution of CADR } \\
\hline
\end{tabular}




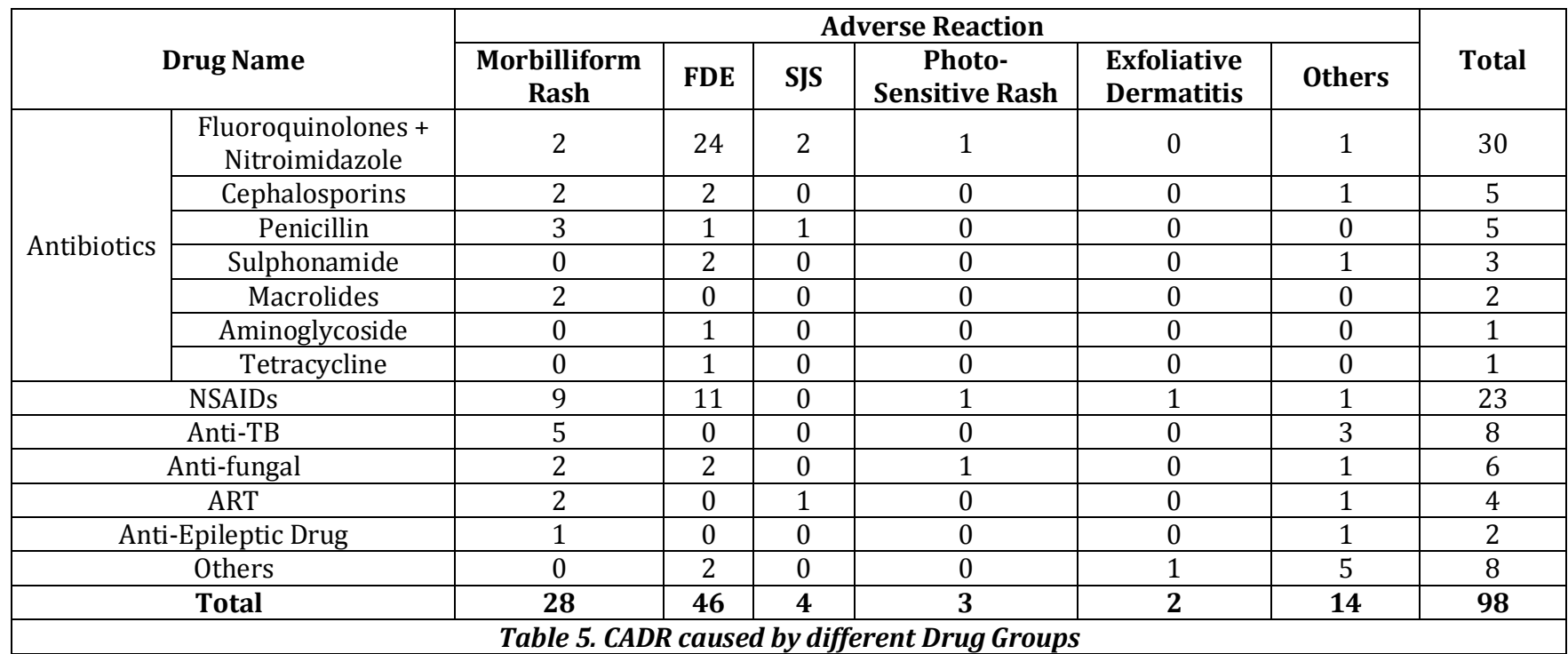

\begin{tabular}{|c|c|c|c|c|c|c|}
\hline $\begin{array}{l}\text { CADR Types and } \\
\text { Pattern }\end{array}$ & $\begin{array}{c}\text { Sushma } \\
\text { et al,1 } \\
2005\end{array}$ & $\begin{array}{c}\text { Jhaj et al, } 2 \\
1999\end{array}$ & $\begin{array}{c}\text { Sharma } \\
\text { et al, } \\
2001\end{array}$ & \begin{tabular}{|c|} 
Patel and Marfatia \\
et al,4 \\
2008 \\
\end{tabular} & $\begin{array}{c}\text { Saha Abanti } \\
\text { et al,5 } \\
2016\end{array}$ & $\begin{array}{l}\text { Present } \\
\text { Study }\end{array}$ \\
\hline No. of Subjects & $n=56$ & $\mathrm{n}=144$ & $n=500$ & $\mathrm{n}=200$ & $n=53$ & $\mathrm{n}=98$ \\
\hline Sex Ratio (M: F) & $1: 1$ & $1: 1$ & $1: 0.68$ & 1: 0.79 & $1: 1.04$ & $1: 0.46$ \\
\hline $\begin{array}{c}\text { Commonest offending } \\
\text { drug }\end{array}$ & Antiepileptics & Antibiotics & Cotrimoxazole & Cotrimoxazole & $\begin{array}{c}\text { Sulfonamides } \\
\text { (Cotrimoxazole, } \\
\text { Sulfasalazine, DDS) }\end{array}$ & \begin{tabular}{|c} 
Antibiotics \\
(fluoroquinolone \\
+ \\
nitroimidazole) \\
\end{tabular} \\
\hline Morbilliform & $35 \%(2-7 d)$ & $50 \%(\mathrm{NA})$ & $\begin{array}{c}34.6 \% \text { (30 mins } \\
-3 \mathrm{wks})\end{array}$ & $18(\mathrm{NA})$ & $30.1 \%(1-30 \mathrm{D})$ & $28.57 \%(1-10 \mathrm{~d})$ \\
\hline FDE & $4 \%(1 \mathrm{~d})$ & $0 \%$ & $\begin{array}{l}30 \% \text { (2 days- } \\
\text { months) }\end{array}$ & $30.5 \%(\mathrm{NA})$ & $24.5 \%(1-30 \mathrm{~d})$ & $46.94 \%(1 \mathrm{~d})$ \\
\hline SJS & $35 \%$ (1-3 wks) & $18.75 \%(\mathrm{NA})$ & $\begin{array}{c}\text { NA (Few hrs. - } 1 \\
\text { wk) }\end{array}$ & $5 \%(\mathrm{NA})$ & $24.5 \%$ (1 h-2 wks) & $4.08 \%(1-5 d)$ \\
\hline Phototoxic & $4 \%(3-4 \mathrm{wks})$ & $0 \%$ & $0 \%$ & $2 \%(\mathrm{NA})$ & $3.8 \%(4-7 d)$ & $3.06 \%(1-5 \mathrm{~d})$ \\
\hline $\begin{array}{l}\text { Urticaria (reported } \\
\text { reaction time) }\end{array}$ & $7 \%(1-3 d)$ & $21.5 \%$ (NA) & $\begin{array}{l}\text { NA (30 mins-3 } \\
\text { wks) }\end{array}$ & $18.5 \%(\mathrm{NA})$ & $5.6 \%(1-28 d)$ & $0 \%$ \\
\hline $\begin{array}{c}\text { Exfoliative dermatitis } \\
\text { (reported reaction } \\
\text { time) }\end{array}$ & $4 \%$ (6 wks) & $0 \%$ & NA (6 wks) & $2.5 \%(\mathrm{NA})$ & $7.54 \%$ (1 d-6 wks) & $2.04 \%(1 \mathrm{~d})$ \\
\hline
\end{tabular}

\section{DISCUSSION}

Our study was conducted in Bundelkhand region of UP, which is considered to be relatively economically backward area of country, where no such type of study has been previously undertaken.

FDE was the most common cutaneous ADR reported in our study. It occurred in 46 of total 98 patients that constitutes $46.94 \%$ of patients. In these FDE patients, fluoroquinolones + nitroimidazole combination was found to be the most common culprit drugs constituting 24 (52.17\%) of patients. This is in contrast to other previous studies, in which FDE cases varied from $4 \%$ to $35 \%$ and Sulphonamides were the most common implicated agent by Sushma ${ }^{1}$ et al and Sharma ${ }^{3}$ et al. The increased percentage of FDE may be due to increase use of Fluoroquinolones combination in comparison to sulphonamides as antibiotics, increased awareness of its efficacy in controlling diarrhoea and dysentery and easy availability of Fluoroquinolones in government supply.

Morbilliform drug rash was the second most common cutaneous adverse drug reaction in $28.57 \%$ of patients (Table 6). In previous study, its incidence varied from $18 \%$ to $50 \%$ of cases. In our study, NSAIDs was the most common cause followed by antibiotics. In NSAIDs Cox inhibitor (nonselective) were the most common cause of CADRs. In antibiotics, cephalosporin 3rd gen. and penicillin was the most common cause of morbilliform cutaneous ADRs.

Serious drug reactions like SJS and TEN occurred in $4.08 \%$ of the cases. In other study, its incidence varied from $5-35 \%$ of patients. Most common cause for SJS were antibiotics, in which fluoroquinolones and penicillins were the most common causative agent in contrast to previous studies, in which sulphonamide used to be the most common culprit drug. Exfoliative dermatitis occurred in $2.04 \%$ of patients. In previous study, its incidence varied from $2.5 \%$ to $7.54 \%$ of patients. Serious side effect was seen less commonly in this study, which may be due to increased awareness among physicians and patients of serious cutaneous adverse drug reactions and early stoppage of drugs.

In most of the cases, patient reported within one day of occurrence of CADRs, which was in $50 \%$ of the patients. In $41.84 \%$ of patients, CADRs was reported in one week. This is similar to study by Sharma ${ }^{3}$ et al and slightly different from study by Sushma ${ }^{1}$ et al. 
In our study most of the CADRs was reported in male patients, $68.36 \%$. This is similar to studies by Sharma ${ }^{3}$ et al, Patel and Marfatia ${ }^{4}$ et al, but in contrast to study by Saha and Avanti $^{5}$ et al. More cases occurring in male patients may be due to greater awareness and increased use of health services by male in comparison to female patients.

Beside antibiotics and NSAIDs, anti-epileptics, antiretroviral and anti-fungal were common groups in which CADRs occurred. Increased CADR due to antifungal may be due to the study being undertaken in Dermatology Department. In ART Nevirapine was the most common drug for CADRs.

\section{CONCLUSION}

From current study, it is concluded that FDE is becoming most prevalent type of cutaneous ADR than Morbilliform drug rash. Commonest culprit drug now are fluoroquinolones + Nitroimidazole combination followed by NSAIDs and Cephalosporins. Cutaneous ADRs are now less reported with sulphonamide, which was the most common culprit drug reported in previous studies. Serious drug reactions like SJS and exfoliative dermatitis are now seen relatively less commonly and in this group too, fluoroquinolones are the predominant culprit drugs.

\section{REFERENCES}

[1] Sushma M, Noel MV, Ritika MC, et al. Cutaneous adverse drug reactions: A 9-year study from a south Indian hospital. Pharmacoepidemiol Drug Saf 2005;14(8):567-70.

[2] Jhaj R, Uppal R, Malhotra S, Bhargava VK. Cutaneous adverse reactions in in-patients in a tertiary care hospital. Indian J Dermatol Venereol Leprol 1999;65(1):14-7.

[3] Sharma VK, Sethuraman G, Kumar B. Cutaneous adverse drug reactions: clinical pattern and causative agents - a 6 year series from Chandigarh, India. J Postgrad Med 2001;47(2):95-9.

[4] Patel RM, Marfatia YS. Clinical study of cutaneous drug eruptions in 200 patients. Indian J Dermatol Venereol Leprol 2008;74(4):430.

[5] Saha A, Das NK, Hazra A, et al. Cutaneous adverse drug reaction profile in a tertiary care outpatient setting in Eastern India. Indian J Pharmacol 2012;44(6):792-7. 